\title{
Postinflammatory Hyperpigmentation Secondary to Liposuction Successfully Treated with a 1,064-nm Picosecond-Domain Neodymium:Yttrium-Aluminum-Garnet Laser
}

\author{
Hae-Jin Lee ${ }^{1}$ \\ Young Koo Kim² \\ ${ }^{1}$ Yonsei A\&B Clinic of Dermatology, Seoul, Korea \\ ${ }^{2}$ Yonsei Star Skin \& Laser Clinic, Seoul, Korea
}

Received December 8, 2019

Accepted December 12, 2019

\section{Correspondence}

Hae-Jin Lee

Yonsei A\&B Clinic of Dermatology, 365

Baekjaegobun-ro Sonpa-gu, Seoul 05616, Korea

Tel.: +82-2-417-7500

Fax: +82-2-417-7503

E-mail: understndahanmail.net

(C) Korean Society for Laser Medicine and Surgery

(c) This is an open access article distributed under the terms of the Creative Commons Attribution NonCommercial License (http://creativecommons.org/ licenses/by-nc/4.0) which permits unrestricted noncommercial use, distribution, and reproduction in any medium, provided the original work is properly cited.
Post inflammatory hyperpigmentation $(\mathrm{PIH})$ is a reactive hypermelanosis of the skin that occurs as a result of various inflammatory responses such as surgical procedure, trauma, and many inflammatory conditions. There are several reported studies of various modality in managing $\mathrm{PIH}$. However, the treatment of PIH can prove to be challenging. In this report, we treated a patient with $\mathrm{PIH}$ using picosecond-domain Nd:YAG lasers. After ten sessions of 1,064-nm picosecond-domain Nd:YAG laser treatment, the patient presented considerable improvement with no remarkable side effects or recurrence over the duration of 6 months. We suggest that a 1,064-nm picosecond-domain $\mathrm{Nd}$ :YAG laser can be effectively and safely used for treating pigmented lesions resulting from surgical procedure in the skin of Asian patients.

\section{Key words}

Postinflammatory hyperpigmentation; Picosecond; Neodymium:yttriumaluminum-garnet laser; Liposuction 


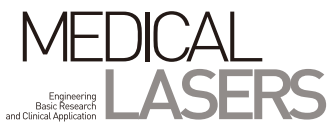

\section{INTRODUCTION}

Postinflammatory hyperpigmentation $(\mathrm{PIH})$ is a reactive hypermelanosis of the skin due to variable inflammatory processes, such as trauma including surgical procedure, and many inflammatory conditions with skin diseases, drug reactions, burns, chemical peelings, and laser applications. ${ }^{1,2} \mathrm{PIH}$ appears as symptom-free macules or patches with variable size and distribution depending on the causative pathology. PIH can also occur in surgical procedure which are frequently performed in clinic and hospital. The skin with PIH has increased melanin production and/or an abnormal distribution of melanin pigment deposited in the skin. ${ }^{1,2}$

There are several options of managing $\mathrm{PIH}$ with medications and procedures including topical application of whitening agents including hydroquinone, azelaic acid, kojic acid, retinoids, vitamin $C$ and chemical peels, laser therapy, and sunscreens. ${ }^{3}$ Among various treatment modalities for $\mathrm{PIH}$, nanosecond-domain lasers have been most widely utilized including the low-dose Q-switched neodymium-doped yttrium aluminum garnet (Nd:YAG) laser, and the fractional $1550 \mathrm{~nm}$ erbium-doped fiber laser. ${ }^{4,5}$ Recently published report showed picoseconddomain of $\mathrm{Nd}$ :YAG lasers have considerable effect in treating $\mathrm{PIH}^{6}{ }^{6}$

Herein, we report an additional case of PIH using 1,064$\mathrm{nm}$ picosecond-domain $\mathrm{Nd}$ :YAG lasers. After weekly ten sessions of 1,064-nm nanosecond-domain Nd:YAG laser treatment, the patient presented considerable improvement in the PIH lesions with no remarkable side effects nor recurrence over the duration of 6 months.

\section{CASE REPORT}

A 39-year-old, Korean woman visited our clinic with 3 month-duration of multiple irregular shaped dark brownish round patches on the both arm which showed the features of $\mathrm{PIH}$. The patient mentioned that the skin lesions occurred after procedure of liposuction (Fig. 1). The patient presented no remarkable treatment history for pigmentation within the last three months. The patient was clinically diagnosed with PIH (Fig. 1A, and B) and was scheduled to undergo laser treatment. After obtaining written informed consent, the patient was treated with weekly 10 sessions of 1,064-nm picosecond domain $\mathrm{Nd}$ :YAG laser treatment (PICOPLUS; Lutronic Corp., Goyang, Koreal performed at the treatment settings of a $6 \mathrm{~mm}$ spot size, a $0.9 \mathrm{~J} / \mathrm{cm}^{2}$ fluence with $10 \mathrm{~Hz}$, and finished each session of treatment when petechiae occurred slightly. The treatment settings were the same for each sessions, and the patient did not complain of side effect during each sessions. The treated areas were cooled with icepacks, and no prophylactic systemic corticosteroids were prescribed. Topical corticosteroids were prescribed due to prevention of erythema after laser therapy. The patient was recommended to apply sunscreen. At 5 months after the first treatment of 1,064-nm picosecond-domain $\mathrm{Nd}$ :YAG laser treatment, the patient presented nearly complete improvement of the PIH lesions without worsening or recurrence (Fig. 1C and D).

\section{DISCUSSION}

Pigmentation disorders occuring after mechanical
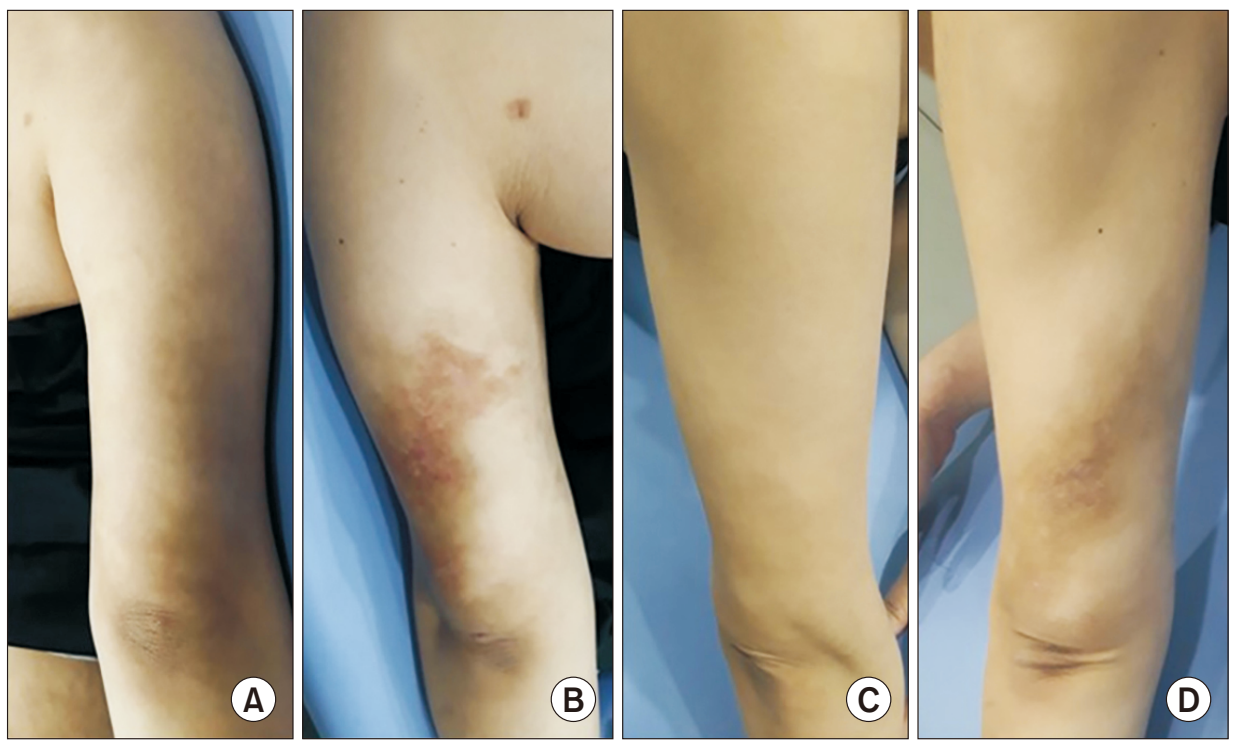

Fig. 1. Photographs of a 39-year-old, Korean female with postinflammatory hyperpigmentation on the both $\operatorname{arm}(\mathrm{A}$; right, $\mathrm{B}$; left) at baseline, $(\mathrm{C}$, D) after weekly 10 sessions of 1,064-nm picosecond-domain neodymium:yttrium-aluminum-garnet laser treatment ( 5 months after baseline). 
trauma including surgical or cosmetic procedures are always a concern, especially in Asians. ${ }^{5}$ Although some cases of $\mathrm{PIH}$ are self-limiting, certain patients with $\mathrm{PIH}$ are needed to treat with several therapeutic modalities including bleaching creams, various laser therapies including Q-switched lasers, which has variable therapeutic outcomes. There are few reports regarding the efficacy of different laser systems including fractional $\mathrm{CO}_{2}$ laser and low-energy Q-switched Nd:YAG laser with nanoseconddomain in the treatment of PIH. ${ }^{2,5} \mathrm{~A} 1064$-nm Q-switched $\mathrm{Nd}$ :YAG with low fluence therapy is easily applicable and the therapeutic trial was revealed to have minimal downtime without post-therapy bleeding or crust formation, and the post-therapy erythema spontaneously resolved within a few hours.

$\mathrm{PIH}$ shows hyperpigmentation due to inflammation and hypermelanosis composed with melanin pigments, which are similar with pigmentations of tattoo. In recent studies, picosecond-domain lasers are more efficacious in removing tattoo pigmentation with less side effects than nanosecond-domain lasers. ${ }^{7}$ Smaller size of particles among target chromophores after consecutive treatment would be better responsive to subsequent picoseconddomain laser treatment than nanosecond domain laser treatment. ${ }^{8}$ Recently, several reports showed picoseconddomain $\mathrm{Nd}$ :YAG laser could be an effective modality to treat $\mathrm{PIH}^{6.9}$ The authors performed weekly or monthly sessions of treatments with nearly complete response. In this report, we also demonstrated near-complete clinical improvement in pigmented lesions after weekly 10 sessions of treatments with 1,064 $\mathrm{nm}$ picosecond-domain $\mathrm{Nd}$ :YAG lasers in a Korean patient with PIH after liposuction procedure. Along with previous report of Lee et al. ${ }^{9}$ and Lee et al., ${ }^{6}$ the laser pulses at the picosecond-pulse duration were seemed to effectively destroy target chromophores. Although further studies are needed to clarify the effective therapeutic doses and duration of 1,064 nm picosecond-domain Nd:YAG lasers, we showed that the weekly treatment of picosecond-domain laser treatments might be an effective therapeutic option of the treatment on $\mathrm{PIH}$.

The authors suggest that 1,064-nm picosecond-domain $\mathrm{Nd}$ :YAG lasers could be effective and safe option of treatment used for managing pigmented lesions in the skin, particularly PIH with various etiology including surgical procedure, in Asian patients. Further prospective, controlled investigations are needed to compare the efficacy and safety of nanosecond- and picosecond-domain lasers and to optimize the treatment settings for $\mathrm{PIH}$.

\section{CONFLICT OF INTEREST}

The authors report no conflicts of interest.

\section{REFERENCES}

1. Callender VD, St Surin-Lord S, Davis EC, Maclin M. Postinflammatory hyperpigmentation: etiologic and therapeutic considerations. Am J Clin Dermatol 2011;12:87-99.

2. Oram Y, Akkaya AD. Refractory postinflammatory hyperpigmentation treated fractional CO2 laser. J Clin Aesthet Dermatol 2014;7:42-4.

3. Katz TM, Goldberg LH, Firoz BF, Friedman PM. Fractional photothermolysis for the treatment of postinflammatory hyperpigmentation. Dermatol Surg 2009;35:1844-8.

4. Rokhsar CK, Ciocon DH. Fractional photothermolysis for the treatment of postinflammatory hyperpigmentation after carbon dioxide laser resurfacing. Dermatol Surg 2009;35:535-7.

5. Cho SB, Park SJ, Kim JS, Kim MJ, Bu TS. Treatment of postinflammatory hyperpigmentation using 1064-nm Q-switched $\mathrm{Nd}: Y A G$ laser with low fluence: report of three cases. J Eur Acad Dermatol Venereol 2009;23:1206-7.

6. Lee HJ, Lee SH, Yoon SY, Kim YJ, Kim YK. Postinflammatory hyperpigmentation secondary to acupuncture and cupping successfully treated with 1,064-nm picosecond-domain neodymium:yttrium-aluminum-garnet Laser. Med Lasers 2019;8:32-4.

7. Ross EV. The picosecond revolution and laser tattoo treatments: are shorter pulses really better? Br J Dermatol 2017; 176:299-300.

8. Ahn KJ, Zheng Z, Kwon TR, Kim BJ, Lee HS, Cho SB. Pattern analysis of laser-tattoo interactions for picosecond- and nanosecond-domain 1,064-nm neodymium-doped yttriumaluminum-garnet lasers in tissue-mimicking phantom. Sci Rep 2017;7:1533.

9. Lee HJ, Lee SH, Yoon SY, Lee JW, Kim YK, Choi EH. Postinflammatory hyperpigmentation successfully treated with 1,064$\mathrm{nm}$ picosecond-domain neodymium:yttrium-aluminum-garnet laser. Med Lasers 2018;7:52-4. 